\title{
QUALIFICAÇÃO DO ENFERMEIRO NO CUIDADO A VÍTIMAS DE VIOLÊNCIA DOMÉSTICA INFANTIL
}

\author{
QUALIFICATION OF NURSES FOR CARE TO CHILD VICTIMS \\ OF DOMESTIC VIOLENCE
}

\section{CUALIFICACIÓN DE LAS ENFERMERAS EN LA ATENCIÓN A LOS NIÑOS VÍCTIMAS DE VIOLENCIA DOMÉSTICA}

\author{
Renata Jabour Saraiva* \\ Ann Mary T. F. Rosas ${ }^{* *}$ \\ Geilsa Soraia C. VAlente*** \\ LIGIA DE O. VIANA ${ }^{* * * *}$
}

\begin{abstract}
RESUMO
Objetivo: Identificar na literatura existente, a importância da atuação do enfermeiro no atendimento às vítimas de violência infantil. Optamos por uma pesquisa bibliográfica do tipo descritiva de abordagem qualitativa. Foi realizada uma busca em bibliotecas virtuais (SciELO, BIREME, LILACS), revistas científicas (Revista Brasileira de Enfermagem, Revista Nursing, RADIS Comunicação em Saúde, Revista Adolescer, Revista Eletrônica de Enfermagem) e legislação vigente, sendo encontrados 99 artigos no período de 2001 a 2010 que atenderam os critérios estabelecidos para a pesquisa. Com a constatação da necessidade de atualização pelos profissionais enfermeiros das unidades de emergência dos hospitais gerais sobre a questão da violência doméstica infantil, de modo a diminuir a negligência em relação à notificação obrigatória e minimizando a reincidência das agressões.
\end{abstract}

Palavras chave: Enfermagem, violência doméstica, maus-tratos infantis.

\begin{abstract}
Objective: To identify the existing literature that addresses nursing care to children victims of domestic violence. We chose a descriptive qualitative bibliographical type approach. A virtual library search (SciELO, BIREME, LILACS), a scientific review (Revista Brasileira de Enfermagem, Revista Nursing, RADIS Comunicação em Saúde, Revista Adolescer, Revista Eletrônica de Enfermagem) and a review of the existing legislation, were held; 99 articles in the period 2001 to 2010 which met the search criteria were found. With this observation, we conclude that it is necessary to update nurses from emergency units of general hospitals on the issue of domestic violence and child abuse, in order to reduce the negligence regarding compulsory notification and minimizing the recurrence of acts of aggression.
\end{abstract}

Key words: Nursing, domestic violence, child abuse.

\footnotetext{
*Mestre em Educação e Enfermagem pela Escola de Enfermagem Anna Nery - UFRJ - Departamento de Metodologia da Enfermagem; Pós-graduanda em Enfermagem Gerontológica da Escola de Enfermagem Aurora de Afonso Costa - Universidade Federal Fluminense - UFF. Email: renata.saraiva@superig.com.br

${ }^{* *}$ Professora adjunto do Departamento de Metodologia da Enfermagem - Escola de Enfermagem Anna Nery - UFRJ. Membro do NUPESENF EEAN/UFRJ. Email: annmaryrosas@gmail.com

${ }^{* * *}$ Professora do Departamento de Fundamentos e Administração em Enfermagem da Escola de Enfermagem Aurora de Afonso Costa - Universidade Federal Fluminense - UFF; Doutoranda em Enfermagem - EEAN/UFRJ. Email: geilsavalente@ yahoo.com.br. Membro do NUPESENF EEAN/UFRJ.

${ }^{* * *}$ Professora titular do Departamento de Metodologia da Enfermagem da Escola de Enfermagem Anna Nery - UFRJ. Doutora em Enfermagem. Membro do NUPESENF EEAN/UFRJ. Email: ligiaviana@uol.com.br.
} 


\section{RESUMEN}

Objetivo: Identificar en la literatura existente la importancia de la enfermera en el cuidado de niños víctimas de violencia. Elegimos un enfoque cualitativo descriptivo de tipo bibliográfico. Se realizó una búsqueda en la biblioteca virtual (SciELO, BIREME, LILACS), revistas científicas (Revista Brasileira de Enfermagem, Revista Nursing, RADIS Comunicação em Saúde, Revista Adolescer, Revista Eletrônica de Enfermagem) y la legislación existente, siendo encontrados 99 artículos en el período 2001 a 2010, que cumplieron los criterios para la búsqueda. Concluimos que es necesario la actualización de las enfermeras de las unidades de emergencia de los hospitales generales sobre el problema de la violencia doméstica infantil, a fin de reducir la negligencia en relación con la notificación obligatoria y reducir al mínimo la repetición de actos de agresión.

Palabras clave: Enfermería, violencia doméstica, maltrato a los niños.

Fecha recepción: 09/04/10 Fecha aceptación: 14/10/11

\section{INTRODUÇÃO}

A violência doméstica infantil se constitui, atualmente, na maior causa de morte de jovens entre 5 e 19 anos, sendo que a maior parte das agressões ocorre no núcleo familiar. Segundo pesquisa realizada pelo Fundo das Nações Unidas para a Infância (UNICEF), de hora em hora morre uma criança queimada, torturada ou espancada pelos próprios pais $12 \%$ das 55,6 milhões de crianças brasileiras menores de 14 anos são vítimas anualmente de alguma forma de violência doméstica. Logo, por ano, são 6,6 milhões de crianças agredidas - em média - 18 mil crianças vitimadas por dia, 750 crianças vitimadas por hora, 12 crianças agredidas por minuto.

A elaboração deste estudo emergiu através da observação na literatura e meios de comunicação, referente ao número de acidentes e violências domésticas que acabam resultando em $64,4 \%$ das mortes de crianças e adolescentes no Brasil. "Trata-se de um problema que acomete ambos os sexos e não costuma obedecer nenhum nível social, econômico, religioso ou cultural específico" (1).

Outro ponto importante observado em campo de prática, com os estagiários do Curso de Graduação em Enfermagem em saúde da criança, refere-se à ausência de capacitação de alguns enfermeiros, por ainda não estarem devidamente qualificados para reconhecer os sinais de violência nas crianças e adolescentes e nem como agir quando o caso é confirmado.

Através deste estudo pretendemos evidenciar os tipos de violência e de acidentes sofridos e se o enfermeiro está qualificado para prestar este atendimento. Sendo assim, apresentamos como objeto de estudo: O papel do enfermeiro frente às vítimas de violência doméstica infantil, partindo do seguinte problema: O enfermeiro está qualificado para reconhecer os sinais de violência doméstica infantil? Como objetivo do estudo: identificar na literatura existente, a importância da atuação do enfermeiro no atendimento às vítimas de violência infantil.

A relevância do estudo decorre dos seguintes aspectos: primeiro, devido ao sofrimento indescritível que a violência doméstica infantil imputa às suas vítimas, muitas vezes silenciosas; em segundo, porque, comprovadamente, a violência doméstica, incluindo a negligência precoce e o abuso sexual, pode impedir um bom desenvolvimento físico e mental da vítima, e terceiro, porque percebemos que sobre esta temática, pouco se tem pesquisado na Enfermagem.

Dessa forma, acreditamos que o profissional mais indicado para essa tarefa é o enfermeiro, pois desde a graduação somos preparados para cuidar do indivíduo como um 
todo e não só como uma patologia. O enfermeiro qualificado para esse tipo de atendimento contribuirá, inclusive, para a rapidez no diagnóstico e tratamento dos clientes (2).

Portanto, o enfermeiro aprende a enxergar as diversas nuances da complexidade humana, devendo especialmente no caso concreto que se apresenta ser dispensada maior atenção quanto aos aspectos psicológicos e fisiológicos, como forma de minimizar os efeitos causados ao paciente, e neste estudo, enfocamos especificamente a criança vitima de violência.

\section{METODOLOGIA}

Este estudo trata de pesquisa bibliográfica do tipo descritiva de abordagem qualitativa. Escolhemos esse tipo de pesquisa por ser uma abordagem baseada em material de estudiosos qualificados, que fizeram pesquisas científicas merecedoras de crédito acerca do tema escolhido.

Para a coleta de dados, efetuamos busca em banco de dados da Biblioteca Virtual de Saúde - Base de dados LILACS, MEDLINE, SchiELO, BDENF, ADOLEC, periódicos científicos, sites de buscas e legislação vigen- te, utilizando as palavras chave: enfermagem, violência doméstica, maus-tratos infantis.

\section{RESULTADOS E DISCUSSÃO}

Fizemos uma leitura interpretativa das obras, quando relacionamos o que os autores consolidaram com a questão, com a intenção de fundamentarmos na busca de uma evidência teórica clara, coesa e concisa, procedendo à seleção do material que interessava ao estudo.

Após a fase de seleção, procedeu-se a leitura e classificação dos dados, utilizando-se um instrumento de coleta onde foram registradas e agrupadas as informações necessárias para a revisão da leitura: título, autor, local de produção, base de dados, ano do estudo, ano da publicação, tipo de publicação, tipo de leitura.

Foram obtidos, 99 artigos, com os critérios de busca: ano de publicação (2001 a 2010), área de conhecimento (enfermagem, pediatria, e psiquiatria), idioma (Português, Inglês, Alemão, Francês, Espanhol), enfoque do conteúdo (violência doméstica infantil), composição (emfermagem, violência doméstica, infantil) (Tabela 1).

Tabela 1. Estado da Arte - banco de dados Biblioteca Virtual de Saúde - Área de Conhecimento - Enfermagem.

\begin{tabular}{|c|c|c|c|c|}
\hline BASE DE DADOS & $\begin{array}{l}\text { NÚMERO } \\
\text { ARTIGOS }\end{array}$ & $\begin{array}{l}\text { RECORTE } \\
\text { TEMPORAL }\end{array}$ & IDIOMA & COMPOSIÇÕES \\
\hline LILACS & 22 & 2005 a 2007 & $\begin{array}{l}\text { Português - } 16 \\
\text { Inglês - } 04 \\
\text { Espanhol - } 02\end{array}$ & $\begin{array}{l}\text { enfermagem; violência } \\
\text { doméstica; infantil. }\end{array}$ \\
\hline MEDLINE & 45 & 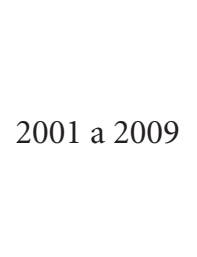 & $\begin{array}{l}\text { Inglês - } 41 \\
\text { Alemão - } 02 \\
\text { Português - } 01 \\
\text { Francês - } 01\end{array}$ & $\begin{array}{l}\text { enfermagem; violência } \\
\text { doméstica; infantil. }\end{array}$ \\
\hline
\end{tabular}


Continuação Tabela 1.

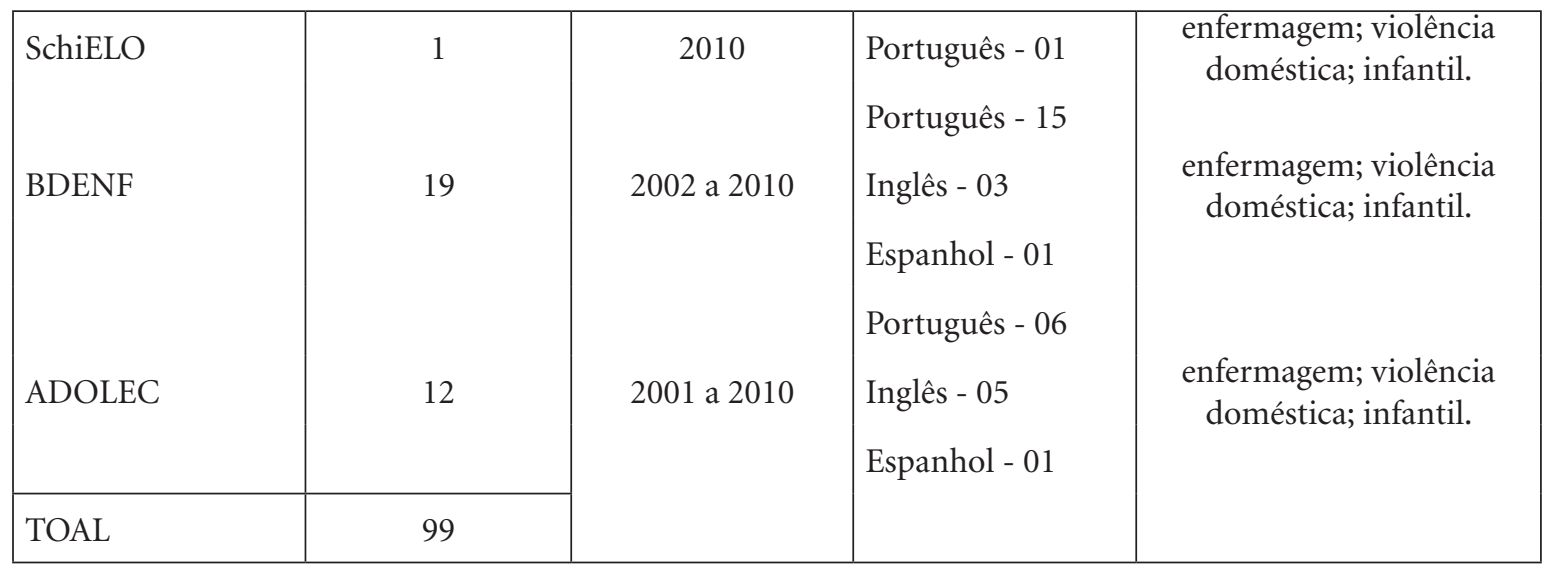

Fonte : elaboração própria.

A análise de dados ocorreu a partir da seleção do material bibliográfico, através de categorias temáticas trazidas pelos resultados de pesquisas de outros estudiosos sobre a temática, iniciando pelo ano de 2001 a 2010, seguindo a construção lógica do trabalho, onde "Consiste na organização das idéias com vistas a atender aos objetivos ou testar a hipóteses formuladas no início da pesquisa" (3).

Da análise temática surgiram duas categorias principais, relacionadas da seguinte forma: Categoria 1. Identificar as sequelas físicas e psicológicas causadas às vítimas e Categoria 2. Descrever a importância de qualificação profissional do enfermeiro no atendimento às vítimas de violência infantil.

\section{Categoria 1. Sequelas físicas e psicológicas causadas nas vítimas}

A violência contra crianças e adolescentes sempre marcou a história da humanidade, mas somente nas últimas décadas, com a criação de associações e centros de proteção à criança, tem recebido a atenção devida (4).

Ainda de acordo com os autores os acidentes transformaram-se em um dos mais graves problemas de saúde pública em todo o mundo, atingindo 40 milhões de crianças de 0 a 14 anos. Com isso, chamou a atenção de diversas instituições governamentais e não governamentais, por ser o responsável pelo aumento da morbimortalidade da população e pelo elevado custo financeiro para o Sistema Único de Saúde (SUS).

Diante dessa realidade tornam-se necessárias ações, por parte da sociedade, que beneficiem as crianças e resguardem seus direitos. Por essa razão, em 1990 foi criado o Estatuto da Criança e do Adolescente (ECA), com o intuito de oferecer proteção, direito à vida e consequentemente melhor qualidade de vida, sendo vários de seus artigos destinados à prevenção da violência.

E que, pode ser classificada em dois tipos: extrafamiliar e intrafamiliar. O primeiro tipo pode ser praticado por adultos conhecidos ou desconhecidos da vítima, o segundo, praticado por membros da família, pode se manifestar de muitas maneiras, como: maustratos físicos, violência psicológica, abuso sexual, negligência/abandono, Síndrome de Münchausen By Proxy e Síndrome do Bebê Sacudido (5).

O abuso sexual infantil, definido como qualquer atividade sexual (incluindo intercurso vaginal/anal, contato gênito-oral, contato gênito-genital, carícias em partes íntimas, masturbação, exposição a pornografias ou a adultos mantendo relações sexuais) envolvendo uma criança incapaz de dar seu 
consentimento, é um dos maiores problemas de saúde pública em todo o mundo (6).

A negligência dos responsáveis ajuda a acentuar as causas dos acidentes. Sendo comum desajuste na estrutura familiar, ocorrendo uma transferência de responsabilidade dos cuidados e educação dos filhos entre os familiares (7).

Tais procedimentos acarretam um atraso significativo no desenvolvimento da criança, acarretando sequelas dos mais diferentes tipos de acidentes. Assim, acreditamos na necessidade de campanhas esclarecedoras envolvendo toda a sociedade, no sentido de denunciar as agressões. Sendo este o primeiro passo para proteger essas crianças, e a efetiva atuação qualificada do enfermeiro no atendimento destas crianças, o que muito contribuirá para que os casos sejam devidamente esclarecidos e notificados, visto que este profissional de um modo geral, sempre está na linha de frente do atendimento da rede de saúde.

\section{Acidentes causados pela violência domés- tica}

Os acidentes mais comuns envolvendo crianças são provocados por quedas, arma de fogo, afogamento, engasgos, queimaduras, envenenamentos, sufocação e falta de segurança no transporte. Dentre os locais de ocorrência de acidentes estão sua própria casa ou de parentes (7).

Os acidentes domésticos têm relação com a idade da criança, etapa de desenvolvimento psicomotor, fatores ambientais, educacionais, socioeconômicos e culturais, os quais estão relacionados com o comportamento e estilo de vida. Tendo o óbito como a consequência mais grave dos acidentes, não se pode esquecer a perda dos anos de vida em potencial, visto que, quanto menor a idade de uma pessoa incapacitada ou morta, maior a perda de anos de trabalho.

Percebe-se que existe uma preocupação em mostrar que a incidência dos acidentes é muito alta e dolorosa à criança e aos seus familiares, porém, torna-se necessário que o enfermeiro crie estratégias de qualificação no sentido de torná-lo apto a identificar rapidamente um ato de violência (7).

Com isso, ficou evidenciado que a agressão física é o tipo de violência com maior número de ocorrência, segundo dados, em 2007, do Instituto de Psicologia da Universidade de São Paulo (Tabela 2).

Tabela 2. Síntese de violência doméstica notificada.

\begin{tabular}{|c|c|c|c|c|c|c|c|c|c|c|c|c|}
\hline \multirow{3}{*}{ Ano } & \multicolumn{12}{|c|}{ Modalidade de VDCA - Incidência Pesquisada } \\
\hline & \multicolumn{2}{|c|}{$\begin{array}{l}\text { Violência } \\
\text { Física }\end{array}$} & \multicolumn{2}{|c|}{$\begin{array}{l}\text { Violência } \\
\text { Sexual }\end{array}$} & \multicolumn{2}{|c|}{$\begin{array}{l}\text { Violência } \\
\text { Psicológica }\end{array}$} & \multicolumn{2}{|c|}{ Negligência } & \multicolumn{2}{|c|}{$\begin{array}{l}\text { Violência } \\
\text { Fatal }\end{array}$} & \multicolumn{2}{|c|}{$\begin{array}{c}\text { Total de casos } \\
\text { notificados }\end{array}$} \\
\hline & Qtd & $\%$ & Qtd & $\%$ & Qtd & $\%$ & Qtd & $\%$ & Qtd & $\%$ & Qtd & $\%$ \\
\hline 1996 & 525 & $44,00 \%$ & 95 & $8,00 \%$ & 0 & $0,00 \%$ & 572 & $48,00 \%$ & 0 & $0,00 \%$ & 1.192 & $100,00 \%$ \\
\hline 1997 & 1.240 & $60,10 \%$ & 315 & $15,30 \%$ & 53 & $2,60 \%$ & 456 & $22,10 \%$ & 0 & $0,00 \%$ & 2.064 & $100,00 \%$ \\
\hline 1998 & 2.804 & $22,20 \%$ & 578 & $4,60 \%$ & 2.105 & $16,70 \%$ & 7.148 & $56,60 \%$ & 0 & $0,00 \%$ & 12.635 & $100,00 \%$ \\
\hline 1999 & 2.620 & $39,30 \%$ & 649 & $9,70 \%$ & 893 & $13,40 \%$ & 2.512 & $37,60 \%$ & 0 & $0,00 \%$ & 6.674 & $100,00 \%$ \\
\hline 2000 & 4.330 & $38,90 \%$ & 978 & $8,80 \%$ & 1.493 & $13,40 \%$ & 4.205 & $37,70 \%$ & 135 & $1,20 \%$ & 11.141 & $100,00 \%$ \\
\hline 2001 & 6.675 & $32,90 \%$ & 1.723 & $8,50 \%$ & 3.893 & $19,20 \%$ & 7.713 & $38,10 \%$ & 257 & $1,30 \%$ & 20.261 & $100,00 \%$ \\
\hline 2002 & 5.721 & $35,80 \%$ & 1.728 & $10,80 \%$ & 2.685 & $16,80 \%$ & 5.798 & $36,30 \%$ & 42 & $0,30 \%$ & 15.974 & $100,00 \%$ \\
\hline 2003 & 6.497 & $31,30 \%$ & 2.599 & $12,50 \%$ & 2.952 & $14,20 \%$ & 8.687 & $41,90 \%$ & 22 & $0,10 \%$ & 20.757 & $100,00 \%$ \\
\hline
\end{tabular}


Continuação Tabela 2.

\begin{tabular}{|rrr|rr|rr|rr|rr|rr|}
\hline $\mathbf{2 0 0 4}$ & 6.066 & $31,00 \%$ & 2.573 & $13,20 \%$ & 3.097 & $15,80 \%$ & 7.799 & $39,90 \%$ & 17 & $0,10 \%$ & 19.552 & $100,00 \%$ \\
\hline $\mathbf{2 0 0 5}$ & 5.109 & $26,50 \%$ & 2.731 & $14,20 \%$ & 3.633 & $18,90 \%$ & 7.740 & $40,20 \%$ & 32 & $0,20 \%$ & 19.245 & $100,00 \%$ \\
\hline $\mathbf{2 0 0 6}$ & 4.954 & $26,70 \%$ & 2.456 & $13,20 \%$ & 3.501 & $18,90 \%$ & 7.617 & $41,10 \%$ & 17 & $0,10 \%$ & 18.545 & $100,00 \%$ \\
\hline $\mathbf{2 0 0 7}$ & 2.940 & $25,10 \%$ & 1.057 & $9,00 \%$ & 2.285 & $19,50 \%$ & 5.422 & $46,30 \%$ & 10 & $0,10 \%$ & 11.714 & $100,00 \%$ \\
\hline Total & $\mathbf{4 9 . 4 8 1}$ & $\mathbf{3 1 , 0 0 \%}$ & $\mathbf{1 7 . 4 8 2}$ & $\mathbf{1 0 , 9 0 \%}$ & $\mathbf{2 6 . 5 9 0}$ & $\mathbf{1 6 , 6 0} \%$ & $\mathbf{6 5 . 6 6 9}$ & $\mathbf{4 1 , 1 0 \%}$ & $\mathbf{5 3 2}$ & $\mathbf{0 , 3 0 \%}$ & $\mathbf{1 5 9 . 7 5 4}$ & $\mathbf{1 0 0 , 0 0 \%}$ \\
\hline
\end{tabular}

Fonte: Instituto de Psicologia/USP, (2007) http://www.ip.usp.br/laboratorios/lacri/iceberg.htm

Seja qual for o número de abusos sexuais em crianças apontado pelas estatísticas, devemos ter em mente que, de fato, esse número pode ser bem maior, tendo em vista que às crianças têm medo de contar para alguém o que se passou com elas e a consequência disto, virá em longo prazo, trazendo danos emocionais e psicológicos, pois na infância é moldada grande parte das características afetivas e de personalidade que a criança carrega por toda vida (4).

Outro fato analisado foi o tipo de agressor e que de acordo com os dados estatísticos da Polícia Civil de Pernambuco, também no ano de 2007, serão mostrados na tabela a seguir (Tabela 3).

Tabela 3. Distribuição do tipo de agressor e seu percentual.

\begin{tabular}{|l|c|c|}
\hline \multicolumn{1}{|c|}{ Agressor } & $\mathbf{N}^{\circ}$ & $\%$ \\
\hline Pai & 652 & $\mathbf{3 8}$ \\
\hline Mãe & 579 & $\mathbf{3 3 , 7}$ \\
\hline Padrasto & 148 & $\mathbf{8 , 6}$ \\
\hline Pai/Mãe & 91 & $\mathbf{5 , 3}$ \\
\hline Tio(a) & 86 & $\mathbf{3 , 2}$ \\
\hline Companheiro/Marido & 55 & $\mathbf{1 , 6}$ \\
\hline Irmão(ã) & 28 & $\mathbf{1 , 4}$ \\
\hline Avô(ó) & 24 & $\mathbf{1 , 1}$ \\
\hline Madrasta & 19 & $\mathbf{0 , 7}$ \\
\hline Primo(a) & 12 & $\mathbf{0 , 5}$ \\
\hline Pai/Madrasta & 8 & $\mathbf{0 , 5}$ \\
\hline Cunhado(a) & 8 & $\mathbf{0 , 2}$ \\
\hline Padrasto/Mãe & 3 & $\mathbf{0 , 1}$ \\
\hline Avô e Avó & 2 & $\mathbf{0 , 1}$ \\
\hline Sogro & 1 & $\mathbf{1 0 0}$ \\
\hline Total & 1.716 & $\mathbf{5}$ \\
\hline
\end{tabular}

Fonte: Polícia Civil de Pernambuco (2007), www.policiacivil.pe.gov.br/. 
De acordo com o quadro anterior a violência intrafamiliar é a mais praticada, tendo o pai como o maior agressor, tendo como justificativa, o senso comum de estar "educando" ou "impondo disciplina", daí a necessidade de campanhas educativas, pois a família resiste em aceitar como um ato de violência à ação praticada.

Em maio de 2003, foi criado no Brasil, serviço telefônico para comunicar casos de abuso e exploração sexual de crianças e adolescentes. Com isso, já foi realizado 2.856.996 atendimentos e encaminhados, 182 mil denúncias em todo o país. No primeiro semestre de 2011, o maior número de denúncias veio da região Nordeste, com 37\% dos atendimentos, seguida da região Sudeste, com 33\% (8).

Portanto, observamos no estudo que os maus-tratos psicológicos são mais difíceis de serem detectados, por não apresentarem um quadro clínico específico. Podendo desenvolver distúrbios do crescimento, do controle de esfíncteres, de comportamento (agressividade, passividade, hiperatividade), baixa autoestima e depressão.

\section{Categoria 2. A importância de qualificação profissional do enfermeiro no atendimento às vítimas de violência infantil}

Os enfermeiros que trabalham no atendimento a essas vítimas deveriam ter o conhecimento de que a violência psicológica é definida como toda ação ou omissão que causa ou visa causar dano à autoestima, à identidade ou ao desenvolvimento da pessoa (4).

Mesmo existindo orientações como a Portaria/GM No 251, que destaca a necessidade da educação continuada, poucos são os artigos a respeito de como o enfermeiro deve atuar na assistência com relação às vítimas de violência doméstica. O silêncio, não só do enfermeiro, mas de todos os profissionais envolvidos no atendimento, parentes, amigos e vizinhos, contribui também para a incidência de novos casos (9).
Observamos nos estágios realizados durante o curso de Graduação em Enfermagem e comprovamos nesta pesquisa que o enfermeiro necessita estar qualificado para identificar os sintomas, contribuindo com isso, para uma possível reincidência da agressão.

Segundo dados da RADIS ${ }^{1}$, a importância da notificação no caso de uma suspeita de violência é um dever de todo profissional de saúde, sendo inclusive, obrigatoriamente comunicados ao Conselho Tutelar da respectiva localidade, sem prejuízo de outras medidas legais cabíveis.

Mesmo estando respaldados por lei, muitos têm receio de fazer a notificação. As causas mais comuns encontradas no estudo são: medo de retaliação, medo da convocação para servir de testemunha em processo criminal e desconhecimento da legislação. $\mathrm{O}$ fato do profissional não denunciar a agressão, acaba por praticar, também, um ato de violência e negligência.

Uma criança que passa várias vezes pelos serviços de saúde sem nenhum tipo de notificação pode não voltar com vida, pois a tendência é que o grau de violência para com ela aumente. Logo, boa parte dos profissionais envolvidos não tem formação adequada para identificar casos de maus-tratos, especialmente os que não deixam marcas físicas evidentes (4).

Ainda de acordo com a RADIS ${ }^{2}$, a notificação não visa somente à punição, restrita às situações mais graves, mas também a educação dos pais. Assim, existem várias formas de prevenir a reincidência da violência doméstica infantil:

\section{1) Fornecer suporte psicológico - quando o agressor é externo à família, o abuso é mais facilmente revelado, porém a fa- mília interrompe o suporte, pois acre-}

\footnotetext{
${ }^{1}$ Revista RADIS - Comunicação em Saúde. 2008. v 70, p. 8. ${ }^{2}$ Revista RADIS - Comunicação em Saúde. 2008. v 70, p. 9-10.
} 
dita que somente o agravo físico requer acompanhamento. Temos como exemplo de interrupção o estupro. A família vê o acompanhamento como forma de reviver a violência;

2) Estabelecer vínculo com a pessoa que levou a criança para ser atendida - esse tipo de violência é praticada por um membro da família, mas mesmo assim, tenta ocultá-la. A proximidade do agressor eleva o risco de reincidência, e a negação implica todo o núcleo familiar, muitas vezes conivente;

3) Fortalecer quem fez a denúncia e proteger a criança - a violência é pratica por um membro da família, e é trazida como queixa. A pessoa que denunciou expõe o agressor e se expõe, deflagrando conflitos;

4) Educar e disciplinar - a agressão é praticada por um membro da família, e outro parente ou o próprio agressor chega a emergência sem identificar a ação como violenta, em geral, ocorre uma resistência da família em aceitar a ação praticada como uma agressão. A ação praticada é vista como "educar" ou "disciplinar" a criança. Nesse caso o risco de reincidência é muito grande, pois toda a família precisa de apoio psicológico e educacional.

Por isso, levando em consideração toda a formação acadêmica, acreditamos que o enfermeiro é o profissional mais indicado para atuar como educador, proporcionando suporte emocional a vítima e a família.

\section{A qualificação profissional do enfermeiro no atendimento}

Sobre este aspecto, a maioria dos profissionais de saúde não tem formação adequada para identificar casos de maus-tratos, especialmente os que não deixam marcas físicas evidentes, embora as sequelas psicológicas sejam quase sempre graves.

A ausência de reconhecimento implica na negligência e na reincidência, sendo necessário qualificar profissionais que saibam cuidar e que tenham conhecimento legal e ético. Acreditamos que este tipo de olhar deveria ser discutido desde a formação inicial na Graduação em Enfermagem, e continuado em curso de pós-graduação específico.

Mesmo existindo orientações como o Estatuto da Criança e do Adolescente, no capítulo que trata do direito à saúde, artigo 13, estabelece: "os casos de suspeita ou confirmação de maus-tratos contra criança ou adolescente serão obrigatoriamente comunicados ao Conselho Tutelar da respectiva localidade, sem prejuízo de outras providências legais". Existe uma grande resistência dos profissionais envolvidos em relação à notificação compulsória (9).

A RADIS ${ }^{3}$ cita que, além do estatuto, existe um guia de atuação frente a maus-tratos na infância e na adolescência, lançado em 2001, destinados aos pediatras e outros profissionais que trabalham com crianças e adolescentes. Elaborado pela Sociedade Brasileira de Pediatria e pelos Ministérios da Saúde e da Justiça, estando, inclusive, disponível pela internet.

Trata-se de um documento minucioso, que tem como objetivo orientar os profissionais na definição de maus-tratos físicos e psicológicos, inclusive, sinalizando a dificuldade de reconhecimento. O guia faz uma ressalva quanto à contextualização, pois cada caso é um caso. Notificar é o primeiro passo, mas só isso não basta, é preciso que o enfermeiro seja qualificado para saber qual será o passo seguinte a ser tomado, pois de nada adianta se nenhuma providência for tomada em seguida. Outras intervenções devem ocorrer, abrindo caminho para o atendimento como um todo, sendo preciso que toda a rede multidisciplinar existente atue, não só da área de saúde, mas também toda a rede social extrahospitalar, tornando-se obriga-

${ }^{3}$ Revista RADIS - Comunicação em Saúde. 2008. v 70, p. 8-11. 
ção de todos, proporcionar o suporte adequado à criança, com atenção psicossocial a que ela tem direito.

A necessidade de qualificação está diretamente ligada à prevenção da reincidência e a novos casos, pois a identificação no primeiro atendimento torna-se cada vez mais necessário, uma vez que temos um aumento de casos de violência infantil intrafamiliar, levando em consideração que essas crianças em sua grande maioria são levadas ao hospital por alguém da família. O profissional deve estar atento para perceber os sinais evidentes, não só no aspecto físico, mas principalmente o psicológico.

O enfermeiro qualificado observa já na primeira entrevista se a lesão é compatível com a história relatada pela família e pelo comportamento da criança. Ficando claramente percebido que a fratura de um braço não poderia ter sido causada por uma queda de bicicleta, como na maioria das vezes é alegado pelo familiar. Relatos discordantes, acidentes recorrentes, sinais de alcoolismo e uso de drogas e busca tardia de socorro precisam ser atentamente observados.

Segundo a RADIS ${ }^{4}$, apesar da existência de vários mecanismos de apoio aos profissionais envolvidos na assistência, ficou evidenciada a carência de qualificação do profissional enfermeiro. Atualmente, existe a política de educação permanente e continuada para os profissionais das áreas de saúde, educação, assistência social e segurança pública dos serviços estaduais de saúde, qualificados em violência pelo Centro Latino-Americano de Estudos de Violência e Saúde Jorge Carelli (Claves/Ensp/Fiocruz), financiado pelo Ministério da Saúde.

Em todos os casos de agressão, é imprescindível que os profissionais envolvidos, em especial o enfermeiro (por estar mais tempo com a vítima), esteja qualificado para o manejo clínico e psicológico, incluindo o

4 Revista RADIS - Comunicação em Saúde. 2008. v 70, p. $8-11$. conhecimento da legislação específica. Para isso é necessário sensibilidade, disponibilidade e experiência. O silêncio do profissional é encarado pelo paciente como novo processo de violência.

A necessidade em educar e qualificar o profissional se deve ao fato de poder proporcionar uma melhor assistência ao paciente que depende dos serviços da organização hospitalar (10).

A educação continuada é aquela que irá capacitar às pessoas não só para as mudanças desejadas pela instituição, como também para as requeridas pela sociedade, proporcionando um desenvolvimento profissional e pessoal. Neste sentido, a enfermagem é uma profissão que requer constante atualização, devido à evolução tecnológica e científica, visto que, o enfermeiro é um educador em todos os campos de atuação (11).

\section{CONSIDERAÇÕES FINAIS}

Fundamentado no material analisado, ficou demonstrado à importância da qualificação do enfermeiro que trabalha no atendimento dos pacientes vítimas de violência doméstica infantil, pois a competência assume destaque na qualidade do cuidado.

Procuramos mostrar ao longo de nossa pesquisa, o entendimento de estudiosos sobre a temática em foco, e o que mais ficou evidenciado, foi à ausência de reconhecimento diante do ato de violência, principalmente devido à carência de qualificação profissional específica do enfermeiro no que tange à atuação frente à criança vitima de violência doméstica, pois ainda estão passando por um processo evolutivo em suas ações, funções e atribuições, ainda não condizentes com a implicação social que tal fato imputa.

É papel e dever do enfermeiro, ser capaz de atuar para a prevenção da violência doméstica infantil, de diagnosticar o risco e le- 
vantar a suspeita precocemente, quando a situação de agressão já está instalada, chegando ao diagnóstico e à denúncia em tempo hábil, para que possa garantir a integridade física e emocional da criança ou adolescente sob seus cuidados. Logo, a partir do atendimento de rotina, emergencial ou de acompanhamento, poderão ser desencadeados todos os meios de proteção legal e social existentes, que devem garantir, ao mínimo, o tratamento da criança ou do adolescente, sua proteção, apoio e assistência familiar, bem como o afastamento do agressor.

Assim, a atenção permanente, continuada e especializada da saúde física e emocional da criança e/ou adolescente vítimas da violência doméstica, bem como de sua família, deverá ser feita por uma equipe multidisciplinar. De sua qualidade dependerá o restabelecimento da autoestima e da integridade física e psíquica das vítimas, reestruturando sua confiança nas pessoas e sua capacidade de lutar dignamente pela vida.

É, portanto, dever ético, legal e moral, de todo profissional envolvido no atendimento estar qualificado e apto para intervir precocemente com as medidas necessárias cabíveis, evitando a reincidência e o aumento das sequelas produzidas pela agressão sofrida. O enfermeiro precisa ser uma pessoa tranqüila, ágil, de raciocínio rápido, de forma a adaptar-se, de imediato, a cada situação que se apresente à sua frente, por isso a necessidade de qualificação, pois deve estar preparado para o enfrentamento de intercorrências emergentes, necessitando para isso, conhecimento científico e competência clínica.

Acreditamos que o olhar diferenciado, que pode enxergar detalhe e ouvir as queixas de dores não faladas, seguido do desencadeamento de todas as medidas de proteção necessárias, é o caminho certo para combater a violência vivida por crianças e adolescentes, no âmbito familiar.

\section{REFERÊNCIAS}

1. Fundo das Nações Unidas para a Infância. The State of the Word's Children [Internet]. New York: Oxford University Press; 1997 [citado 27 abr 2011]. Disponível em: http://www.unicef.org/sowc97/ report/.

2. Saraiva RJ. A Consulta de Enfermagem ao Adulto Idoso - Uma Análise Compreensiva como Contribuição para o Ensino. [Dissertação]. [Rio de Janeiro (RJ)]: Escola de Enfermagem Anna Nery/UFRJ; 2011.

3. Gil AC. Como elaborar projetos de pesquisa. 3ed. São Paulo: Atlas; 2002. p. 4546.

4. Terra FS, Santos LES. A violência doméstica e a criança. REME rev. min. enferm [Internet]. 2006; 10 (3) [citado 27 abr 2011]. Disponível em: www.enf.ufmg.br/ reme.php.

5. Ballone GJ. Violência doméstica. Psiq Web. [Internet]. 2003 [citado 26 abr 2011]. Disponível em: http://virtualpsy. locaweb.com.br/.

6. Palusci VJ, Palusci JV. Instrumentos de avaliação de abuso sexual em crianças. J Pediatr (Rio J). 2006; 82 (6): 431-436.

7. Regiani C, Correa I. Acidentes na infância em ambiente domiciliar. REME rev. min. enferm. [Internet]. 2006; 10 (3): 277-79. [citado 26 abr 2011]. Disponível em: www.enf.ufmg.br/reme.php.

8. Brasil. Portaria/GM No 251. Portaria que estabelece: diretrizes e normas para a assistência hospitalar em psiquiatria, reclassificam os hospitais psiquiátricos, define e estrutura a porta de entrada para as internações psiquiátricas na rede do SUS. [Internet] Brasília, DF: Ministério da Saúde; 2002 [citado 27 abr 2011]. Disponível em: http://portal.saude.gov.br/ portal/arquivos/pdf/oficio. 
9. Brasil. Lei No 8.069 - Estatuto da Criança e do Adolescente. [Internet] Brasília, DF: Presidência da República; 1990 Feb. [citado 25 jun 2008]. Disponível em: http:// www.planalto.gov.br/ccivil.

10. Souza MCB, Ceribelli MIPF. Enfermagem no centro de material esterilizado - a prática da educação continuada. Rev Lat Am Enfermagem. 2004; 12 (5): 767-74. 11. Girade MG, Cruz EMNT, Stefanelli MC. Educação continuada em enfermaria psiquiátrica: reflexão sobre conceitos. Rev. esc. enferm. USP. 2006; 40(1): 105-110. 